This item was submitted to Loughborough's Research Repository by the author.

Items in Figshare are protected by copyright, with all rights reserved, unless otherwise indicated.

\title{
Evidence based dementia personas: Human factors design for people living with dementia
}

PLEASE CITE THE PUBLISHED VERSION

https://doi.org/10.2478/9783110617832-018

\section{PUBLISHER}

Sciendo, De Gruyter ( The Authors

VERSION

VoR (Version of Record)

\section{PUBLISHER STATEMENT}

This work is made available according to the conditions of the Creative Commons Attribution 4.0 International (CC BY 4.0) licence. Full details of this licence are available at: http://creativecommons.org/licenses/by/4.0/

\section{LICENCE}

CC BY 4.0

\section{REPOSITORY RECORD}

Jais, Charlotte, Sue Hignett, Zuli G. Estupinan, and Eef Hogervorst. 2019. "Evidence Based Dementia Personas: Human Factors Design for People Living with Dementia”. figshare.

https://hdl.handle.net/2134/28376. 


\title{
EVIDENCE BASED DEMENTIA PERSONAS: HUMAN FACTORS DESIGN FOR PEOPLE LIVING WITH DEMENTIA
}

\author{
Charlotte Jais $^{1}$, Sue Hignett ${ }^{1}$, Zuli Galindo Estupiñan ${ }^{2}$, Eef Hogervorst ${ }^{1}$ \\ ${ }^{1}$ Loughborough University, Epinal Way, LE11 3TU Loughborough, United Kingdom, \\ c.jais3@lboro.ac.uk, S.M.Hignett@lboro.ac.uk, E.Hogervorst@lboro.ac.uk \\ ${ }^{2}$ University of Guadalajara, Av. Juárez No. 976, Colonia Centro, C.P., 44100 \\ Guadalajara, Mexico, zulig89@gmail.com
}

\begin{abstract}
The complex needs of people with dementia can create challenges when designing care environments. A Human Factors and Ergonomics (HFE) approach to the design of dementia care environments was used to address this challenge, and support wellbeing and independence for system users. Four individual personas (Alison, Barry, Christine and David) and a couple persona (Chris and Sally) were developed to represent the needs of people living with dementia. The aim was to facilitate the exchange of information and expertise between stakeholders and improve understanding of the characteristics of system users. An evidence-based approach involved extracting information from design, dementia, and clinical literature. This was followed by an iterative persona development process and a validation exercise to review the concept, content and applications. This paper outlines the development process, describes each persona and discusses current and potential applications.
\end{abstract}

Keywords: dementia, personas, care, environment.

\section{Introduction}

Dementia is a significant global issue, with an estimated 46 million people living with dementia worldwide [10]. This number is expected to rise to around 131.5 million people by 2050 [10]. The diverse nature of the symptoms of dementia, including cognitive, perceptual, functional and communicative considerations, results in challenges for providing appropriate care environments.

A Human Factors and Ergonomics (HFE) approach to dementia care design may therefore be useful as this would account for users' limitations whilst supporting users' capabilities, maximising wellbeing and independence and creating systems to fit their users [2].

To support such an approach to dementia design, it is vital that the stakeholders involved in the design process have a good understanding of the range of needs and symptoms associated with dementia in order that these can be 
accounted for. Design tools such as personas are likely to be of use here as they showcase the characteristics of archetypal users of a particular product, meaning that subsequent designs can take these factors into account. Whilst personas are more commonly used in fields such as marketing and software design [1], they have potential use in the context of dementia design as they can be used to highlight the needs, symptoms, limitations and abilities of people with dementia. This may be particularly useful when designing environments for people with more advanced dementia who may be less able to take part in the design process due to more severe communication difficulties. It was proposed that dementia personas could assist stakeholders who have less knowledge of dementia to develop a better understanding of the condition, enabling them to be more mindful of relevant considerations when designing environments for people with dementia.

While the potential usefulness of personas in this context is clear, there are no known pre-existing personas which represent people with dementia; those which have represented older people have focussed more specifically on mobility related concerns (for example, the ArjoHuntleigh mobility gallery). For this reason, this research aimed to develop a set of evidence-based dementia design personas to be used as a discussion tool for stakeholders involved in the development of dementia care environments. The personas needed to be evidence-based rather than assumption-based as they are grounded in research rather than stereotypes or preconceptions that the creators have about a certain user group [1]. The iterative process for the development of these personas is outlined in this paper.

\section{Initial persona development}

A literature review was undertaken to explore current research based recommendations for dementia design. This used a systematic approach to searching databases for relevant literature, assessing the quality of the included literature, and examining and collating the findings of this literature. The review found several areas with near consensus on what was appropriate when designing for dementia; for example, access to outdoor areas [3], and wayfinding cues to correctly identify their bedroom [5,8]. The findings on other aspects of dementia design such as lighting and behaviour were less clear, and there was less consensus, particularly for bright light therapy. One of the main findings of the review was that whilst many of the included papers had referred to one or more activities of daily living, there was limited consideration for activities of daily living that were relevant or important specifically for people with dementia. So, to ensure that the personas were relevant for people to dementia, and included the most important activities, a scoping study was undertaken to identify activities of daily living (ADL) for people with dementia.

ADL are generally considered to include activities such as eating, dressing, and bathing, but it was recognised that because people with dementia may have 
different needs, abilities and limitations, their daily activities may also differ. The scoping study used an online questionnaire which was distributed to stakeholders working in healthcare and design fields related to dementia. These stakeholders included design professionals, for example architects with experience of designing spaces for people with dementia, and healthcare professionals such as occupational therapists and care staff working in dementia care homes. Participants were asked to consider activities which were particularly relevant to or important for people with dementia, as well as recommend design solutions to support these activities. It was found that eating, toileting, social interaction and physical activity were the most important activities, and a range of design solutions were suggested to support these activities that were broadly in line with the guidance in the dementia design literature. These activities were then used to develop the initial set of personas for 4 stages of dementia:

- A: Alison (early stage),

- B: Barry,

- C: Christine/Charles (renamed Christopher/Chris),

- D: David (late stage).

The initial personas (Fig. 1) were presented in a table format, with three sections; personal information, clinical information and design information. The personal information section included the persona name, age, and occupation. The clinical information section included details of the persona cognitive, perceptual, physical and communicative abilities, as well as their diagnosis. The design information section included information on difficulties that the persona had with ADL such as eating and toileting, and recommendations for the design of care environments to reduce the level of difficulty whilst engaging with these activities.

\section{Further persona development}

The initial personas (Version 1: V1) were evaluated with a focus group and interview study to assess whether the content and format were appropriate, and where they should be applied within the design process. As with the scoping study, participants represented a range of occupational backgrounds, including architects, care support workers, and care home developers. It was felt that the format of the V1 personas, was not particularly accessible or engaging and that important information might be missed. As well as this, V1 personas included design guidance for some of the issues such as wayfinding. This was not thought to be necessary as most design professionals working in dementia design would already be aware of these principles, and that where they were not, this information was already readily available in design guidelines. Furthermore, it was suggested that the personas only presented a snapshot each person, and did not adequately describe the fluctuations that could occur both during 24 hours and from day to day. 


\begin{tabular}{|c|c|}
\hline Alison & Female \\
\hline Social information & Widowed \\
\hline Age & 70 \\
\hline Job (current/past) & Retired shop worker \\
\hline Clinical condition & Early stage dementia (Alzheimer's Disease) \\
\hline Current situation & $\begin{array}{l}\text { Planning for long term care and possible future move to care home as disease } \\
\text { progresses }\end{array}$ \\
\hline Physical abilities & Independently mobile, small risk of falls \\
\hline Cognitive abilities & $\begin{array}{l}\text { Short term memory problems, struggles to learn new skills, sometimes forgets } \\
\text { what she has just read }\end{array}$ \\
\hline Perceptual abilities & $\begin{array}{l}\text { May struggle to distinguish between different objects where there is little } \\
\text { contrast }\end{array}$ \\
\hline Communication & Sometimes has difficulties in finding the right word \\
\hline $\begin{array}{l}\text { Built environment } \\
\text { issues }\end{array}$ & $\begin{array}{l}\text { - Alison may find it difficult to locate the bathroom, so it is important that } \\
\text { bathrooms are clearly visible. Signage on walls, doors and floors } \\
\text { could help with this. Signs should use contrasting colours, relevant } \\
\text { images and large, clear text }{ }^{1} \text {. } \\
\text { Alison also faces difficulties inside the bathroom. Contrasting toilet } \\
\text { seats can help to reduce her risk of falls }{ }^{2} \text {, and fixtures such as dual } \\
\text { lever taps which are both familiar and easy to use may enable her to } \\
\text { engage with activities related to toileting such as handwashing }{ }^{3} \text {. } \\
\text { - Signage could also assist Alison in finding the dining room. To help } \\
\text { Alison to remember where she is and why she is there, the dining } \\
\text { room should resemble a typical "homelike" dining room as far as } \\
\text { possible. To prevent falls and injuries, furniture such as tables and } \\
\text { chairs should contrast well with the floor and walls }{ }^{2} \text {. }\end{array}$ \\
\hline \multicolumn{2}{|c|}{$\begin{array}{l}1 \text { Signs with large clear text, high contrast colours and relevant images can help to promote bathroom } \\
\text { finding when placed on walls or floors (1). } \\
2 \text { Reduced contrast sensitivity has been shown to be one of the most important visual risk factors for } \\
\text { falls }(2) \text {. Coloured toilet seats which contrast with the toilet bowl can help to enhance visual abilities } \\
\text { within the bathroom and may help to prevent falls. Similarly, using contrast between the walls, floors } \\
\text { and furniture in dining areas may help to prevent falls occurring here. } \\
{ }^{3} \text { Familiar fixtures may help to avoid confusion and enable people with dementia to complete tasks } \\
\text { such as handwashing more independently (3). } \\
4 \text { Environments which would have looked familiar to a person with dementia during their early } \\
\text { adulthood can help to counteract the difficulties which they experience as a result of dementia (4). }\end{array}$} \\
\hline
\end{tabular}

Fig. 1. Example of an initial persona

Source: own elaboration. 
It was also felt that expanding the personal information section to include details of hobbies and interests would help to make the personas more realistic.

The personas were iteratively redrafted and reviewed (versions 2-5), with major changes to the format. Alongside an updated personal information section, each of the V5 personas contained information on symptoms, care needs and design needs.

These sections were further represented as good, average and bad days, to show how symptoms and needs may change. The V5 personas were presented as a wheel with a rotating cover to reveal colour coded sections (Fig. 2) as a traffic light system, with green for a good day, amber an average day and red a bad day.

A persona representing a couple was also developed to reflect the carers of people living with dementia, albeit not as the dementia persona. This largely followed the same format, but had an inner wheel to represent the needs of the person with dementia (Charles), and an outer wheel representing the needs of his wife and carer, Sally (Fig. 3).

Other changes were also made during the V2 to V5 iterations, including the addition of clinical assessment scores and icons. Clinical assessment scores were added for the Mini Mental State Exam (MMSE; [4]), the Montreal Cognitive Assessment (MoCA; [9]), the Addenbrooke's Clinical Examination III (ACE-III; [7]) and the Abbreviated Mental Test (AMT; [6]). The scores given to each persona were generated through examination of the guidance notes that accompanied each assessment tool, and discussion with an Occupational Therapist with extensive experience of working with people with dementia. Icons were added to illustrate the content within the persona wheels for ease of reference, and represented issues such as eyesight or hearing problems, and requiring assistance with ADL. A matrix was also created for each persona (Figures 4-8) which showed the symptoms, care needs and design needs across a good, average and bad days for each persona without having to scroll through the persona wheel. During this iteration, Charles was renamed Christopher (Chris) to reflect the fact that his symptoms and needs were of a similar level to Christine's symptoms and needs.

\section{Validation of final personas}

The final personas (Version 6, V6: Fig. 4 - Fig. 8) were then validated during a third study. A range of care homes that provided care for people with dementia were recruited to discuss and evaluate the personas with staff including care managers, nurses and care assistants. The homes represented a range of care with some solely accommodating people with dementia, whereas others housed people with dementia and people without dementia, sometimes in separate units. Some of the homes were purpose built, and some of the buildings were older. Participants were introduced to the concept of personas and given copies of the persona wheels. They were asked a series of questions about the personas such as the content and format, and potential usefulness in dementia care home design. 

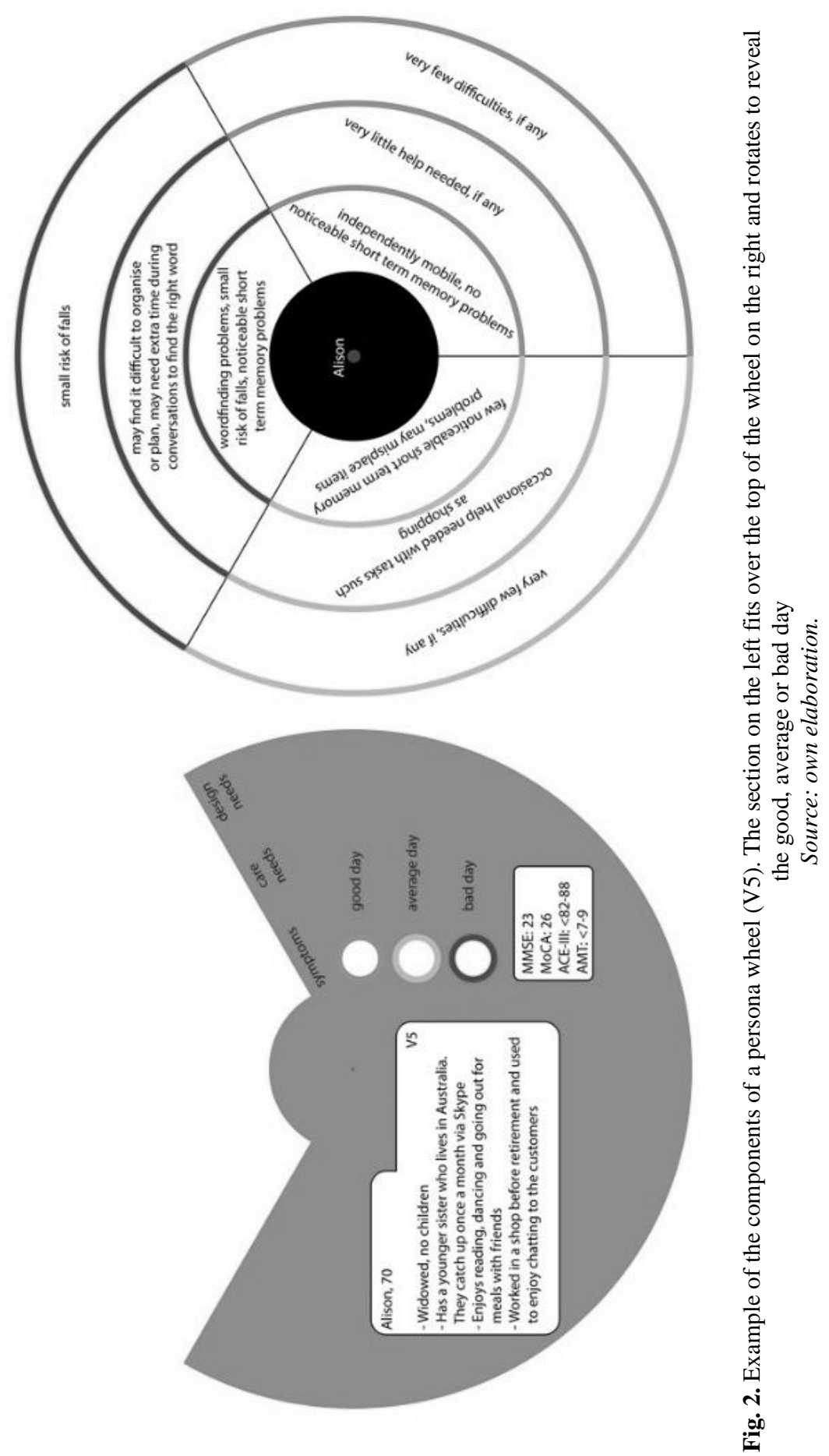


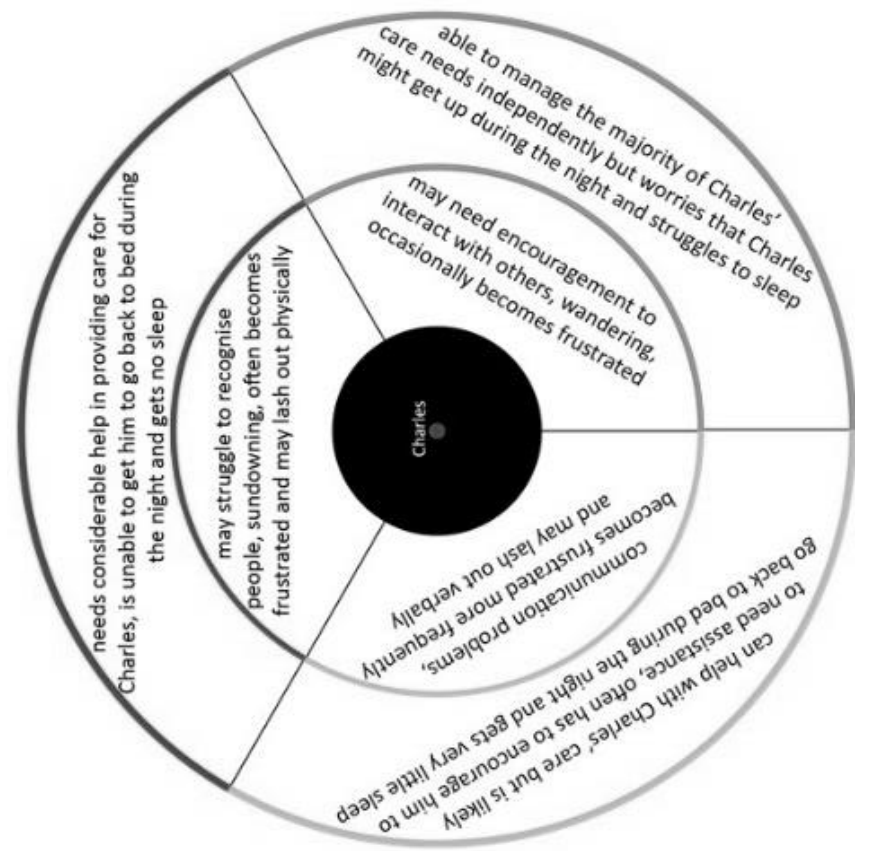

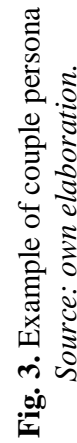

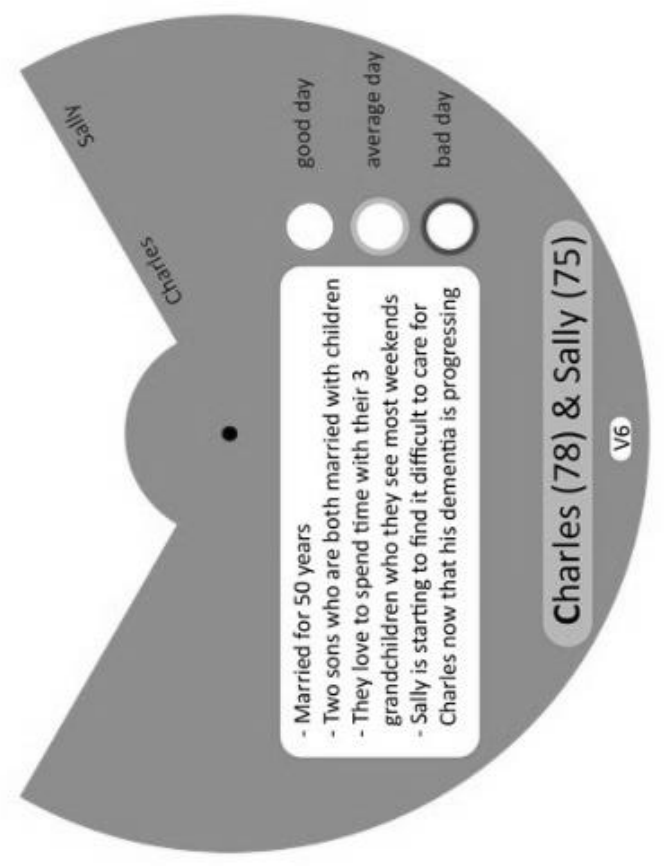




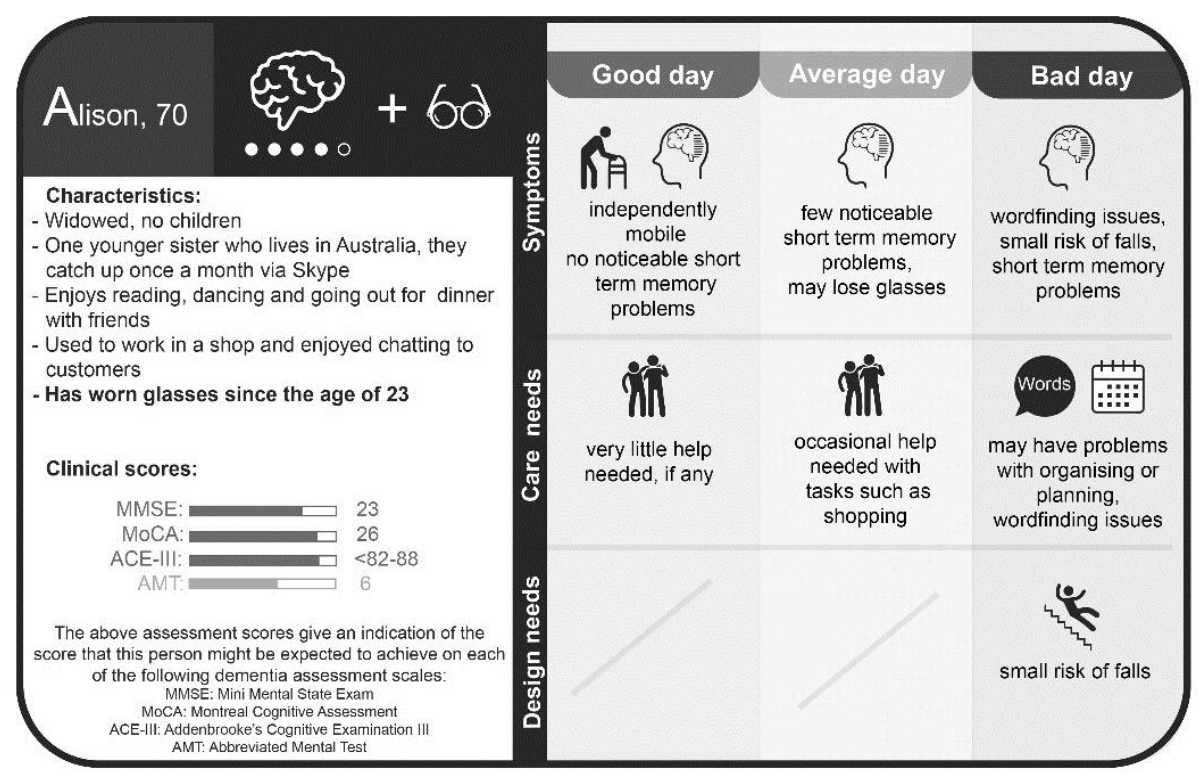

Fig. 4. Final Alison persona (matrix) Source: own elaboration.

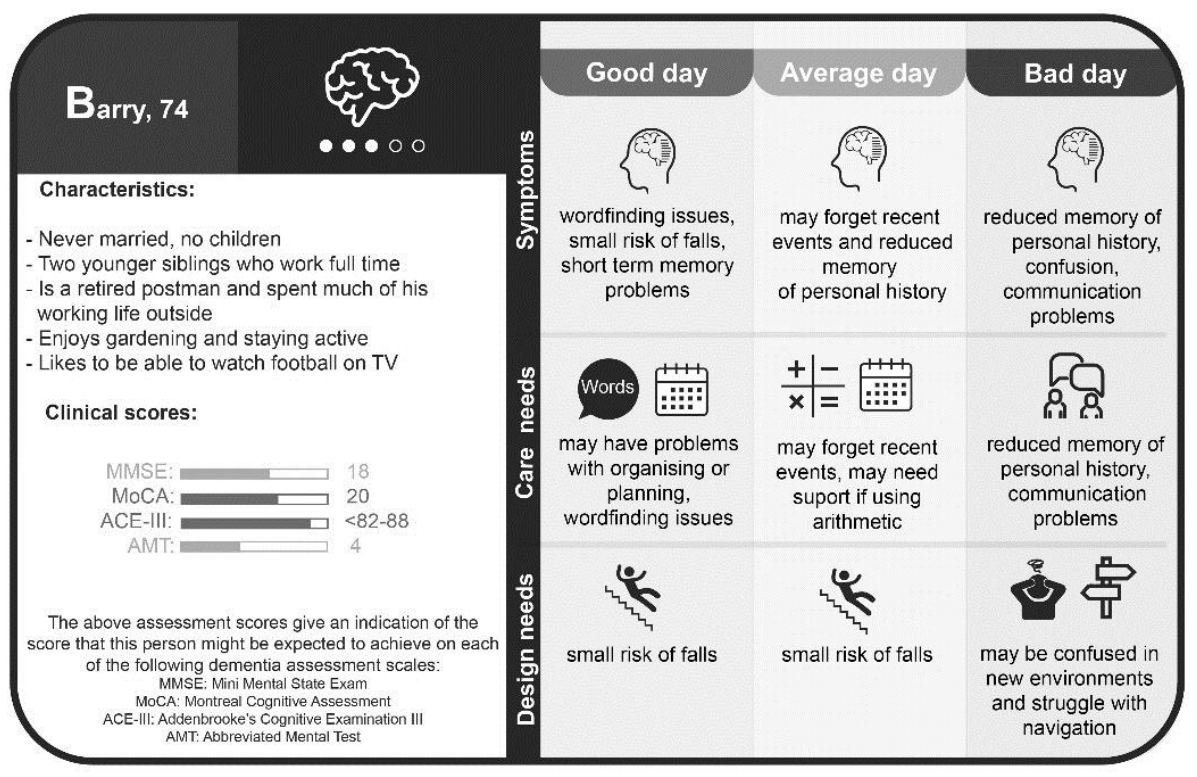

Fig. 5. Final Barry persona (matrix) Source: own elaboration. 


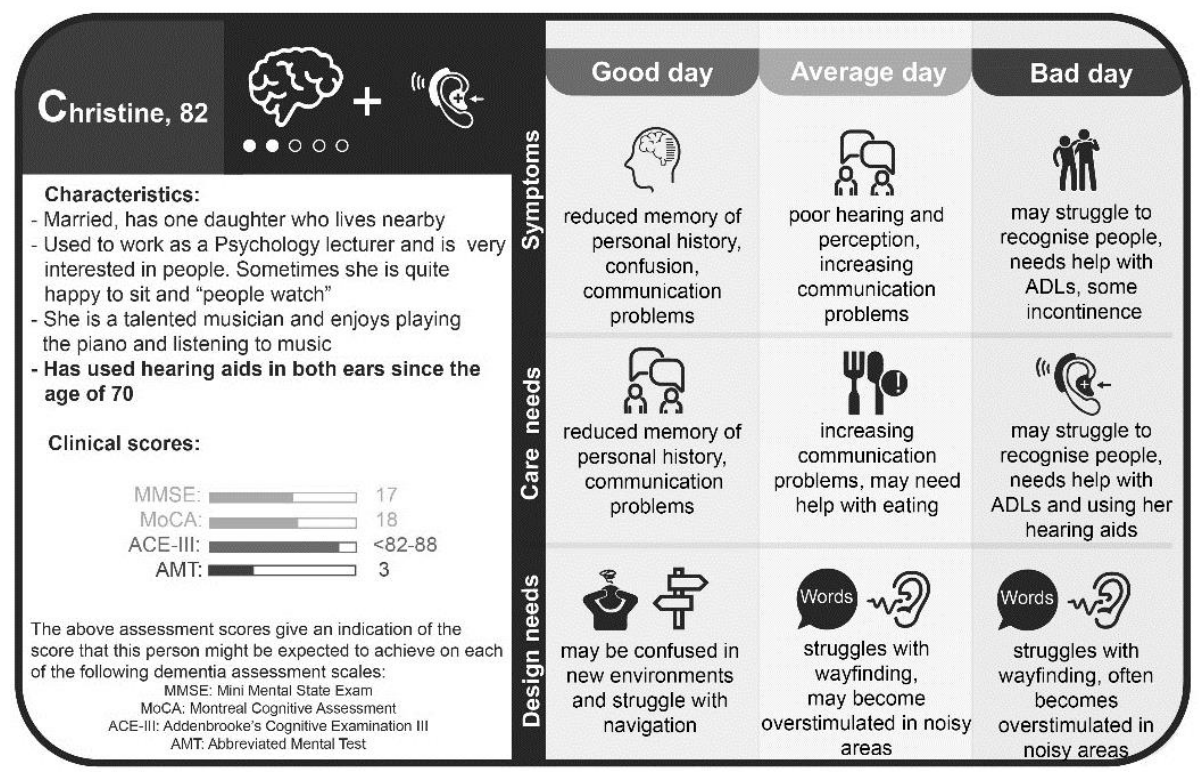

Fig. 6. Final Christine persona (matrix) Source: own elaboration.

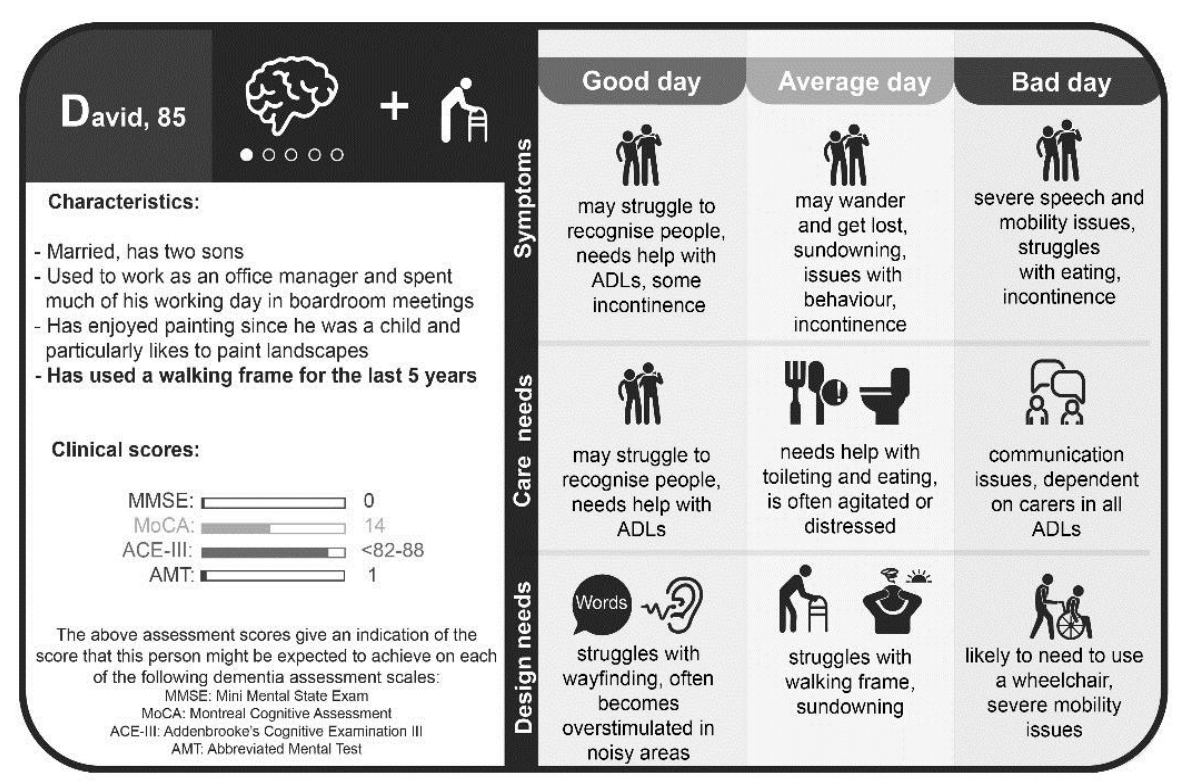

Fig. 7. Final David persona (matrix)

Source: own elaboration. 


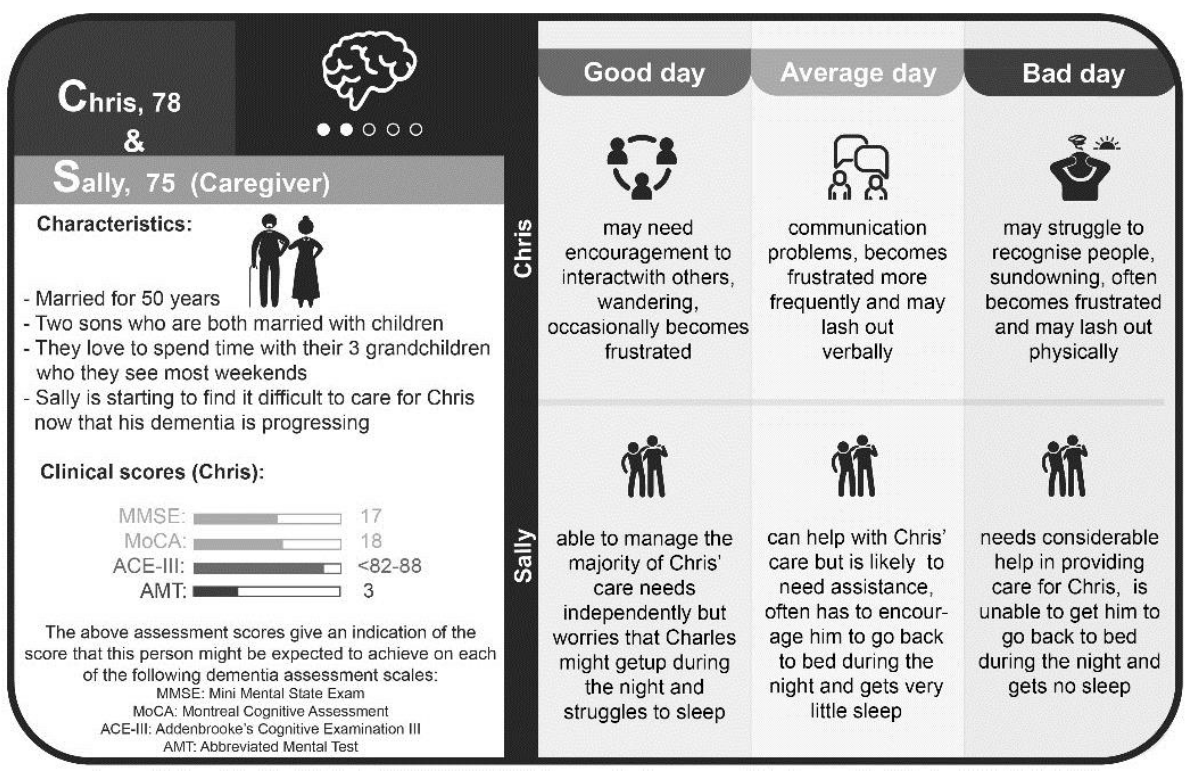

Fig. 8. Final Chris and Sally (Couple) persona (matrix) Source: own elaboration.

Participants were also asked about features of the personas such as the colour coded good-average-bad days, and finally recommendations for further developments and applications. At each home, the researchers and participants discussed building design and environmental layout during a walkabout to explore the application of the personas for features that might be helpful or problematic for people with dementia.

The response to the personas was very positive, with participants suggesting that they were valuable representations of people with dementia and could potentially be adapted to represent actual care home residents for use in care delivery as a communication tool for shift handover. Several participants commented that they "recognised" the personas as needs and symptoms of actual residents. This became more apparent during the walkabout when participants identified features of the home that might cause difficulties for the personas with reference to actual residents. The inclusion of the icons in the final version was reported to be useful for quick reference, and particularly for staff whose first language was not English. The participants felt that the personas were a useful tool, and could see applications in both care home design and care delivery for people with dementia.

\section{Discussion}

This paper has described the use of HFE principles to develop a set of dementia design personas. The fact that these personas are evidence-based is 
a particular strength as it addresses previous critiques of personas which may have been based on preconceptions and stereotypes which can be inaccurate and/or misleading. The results found that basing the personas development on research evidence has improved relevance by focussing on relevant activities (ADL). The initial scoping study specifically identified activities which are important in dementia care. Due to the fact that some of the most important activities identified in the scoping study were social interaction and physical activity, it is unlikely that basing the personas on current classifications of ADL would be adequate as these social interaction and physical activity are considered to be instrumental activities of daily living (iADL; important but non-essential activities) rather than ADL.

The involvement of stakeholders in the development and review of the personas is another strength of this research. This was a particularly important component of persona development to ensure that the content remained relevant and meaningful, and that the format was accessible.

One potential limitation of this research is that people living with dementia were not directly involved in the development of the personas. There were two reasons for this. Firstly, it was noted that while it would be possible to discuss the personas with those with early stage dementia, it may not be for those with more advanced dementia, as this group often struggle with communication. This could have resulted in only two out of four levels for the personas being discussed, which may have caused problems with validity. Secondly, each persona does not represent one specific individual with dementia, they are more generic and represent a range of people at each of the 4 stages. The third study adds validity as participants were able to "recognise" elements of actual residents in each persona suggesting that the personas do successfully represent this diversity.

\section{Conclusion}

This paper outlined the process to develop and validate an evidence based set of dementia personas to aid the design of dementia care environments. Grounding these personas in research evidence, and seeking feedback at various stages, has resulted in a robust and valid set of personas. It is recommended that future research should consider the additional applications for these personas in care delivery, for example at shift handovers.

\section{References}

[1] Adlin, T., Pruitt J.: The Essential Persona Lifecycle - Your Guide to Building and Using Personas 2010.

[2] Dul, J., Bruder, R., Buckle, P., Carayon, P., Falzon, P., Marras, W.S., Wilson, J.R., van der Doelen, B.: A strategy for human factors/ergonomics: developing the discipline and profession. Ergonomics. 55(4), 2012, 377-395. 
[3] Edwards, C.A., McDonnell C., Merl H.: An evaluation of a therapeutic garden's influence on the quality of life of aged care residents with dementia. Dementia. 12(4), 2013, 494-510.

[4] Folstein, M.F., Folstein, S.E., McHugh, P.R.: Mini-mental state. Journal of Psychiatric Research,12(3), 1975, 189-198.

[5] Gross, J., Harmon, M.E., Myers, R.A., Evans, R.L., Kay, N.R., RodriguezCharbonier, S., Herzog, T.R.: Recognition of Self Among Persons With Dementia: Pictures Versus Names as Environments Supports. Environment and Behaviour, 36(3), 2004, 424-454.

[6] Hodkinson, H.M.: Evaluation of a mental test score for assessment of mental impairment in the elderly. Age \& Ageing, 1(4), 1972, 233-238.

[7] Hsieh, S., Schubert, S., Hoon, C., Mioshi, E. Hodges, J.R.: Validation of the Addenbrooke's Cognitive Examination III in Frontotemporal Dementia and Alzheimer's Disease. Dementia and Geriatric Cognitive Disorders, 36, 2013, 242-250.

[8] Kovach, C., Weisman, G., Chaudhury, H., Calkins, M.: Impacts of a therapeutic environment for dementia care. American Journal of Alzheimer's Disease and Other Dementias, 12(3), 1997, 99-110.

[9] Nasreddine, Z., Phillips, N., Bédirian V., Charbonneau, S., Whitehead, V., Collin, I., Cummings, J.L., Chertkow, H.: The Montreal Cognitive Assessment, MoCA: a brief screening tool for mild cognitive impairment. Journal of the American Geriatrics Society, 53(4), 2005, 695-699.

[10] Prince, M., Wimo, A., Guerchet, M., Ali, G-C., Wu, Y-T., Prina, M., Yee Chan, K., Xia, Z.: World Alzheimer Report 2015. The Global Impact of Dementia: An Analysis of Prevalence, Incidence, Cost and Trends 2015. 